\title{
A numerical analysis of buoyancy-driven melting and freezing
}

\author{
T. J. SCANLON*and M. T. STICKLAND \\ University of Strathclyde, Department of Mechanical Engineering, \\ Glasgow G1 1XJ, Scotland
}

\begin{abstract}
A numerical investigation of transient natural convective heat transfer with coupled phase change is presented. The numerical model attempts to capture the solid-fluid interface using a fixedgrid solution and is applied to two pure substance cases found in published literature, one considering the melting of $95 \%$ pure Lauric acid and the other involving the freezing of water. The governing equations are solved in a manner such that if the temperature falls below the freezing isotherm then the convection terms in the equations of motion are effectively disengaged. Variations in the specific heat of the material are incorporated in order to account for the phase change. A non-Boussinesq approach is considered which accounts for any density extrema in the flow, particularly for the density inversion found in water. In both of the cases considered the phase change occurs between fixed temperature boundaries and Rayleigh numbers rest well within the laminar flow regime. From the results obtained it is demonstrated that a relatively simple numerical technique can be applied to capture the physics of buoyancy-driven melting and freezing and that the results are in reasonable concurrence with experimental data.
\end{abstract}

\section{INTRODUCTION}

The analysis of buoyancy-driven flows with coupled solid-liquid phase change is important in a broad range of scientific and engineering fields. Examples of these may be found in the solidification and melting phenomena commonly encountered in metallurgical processes, latent heat thermal energy storage, oceanography, food processing and nuclear reactor safety; see Goldstein and Ramsey [1], Ostrach [2] and Feldman et al. [3]. Such a case involving heat transfer with phase change coupled with a moving solid-fluid boundary is often referred to as a Stefan problem.

In the published literature, a substantial body of numerical and experimental work has been dedicated to the solution of Stefan problems in the presence of buoyancy-driven natural convection. Extensive reviews of such investigations may be found in the publications of Viskanta, [4], Yao and Prusa [5] and Prescott and Incropera [6]. Numerical techniques involved in capturing the physics of such problems fall into two main categories. These are either fixed grid or moving deformable grid solutions. For the fixed grid technique (as concerned in this paper) the standard approach is to follow the conventional enthalpy formulation method in which source terms are incorporated into the governing transport equations in order to inhibit the flow in regions where phase change is assumed to be occurring; see Usmani et al [7], Oosthuizen [8], Swaminathan and Voller [9], Bertand et al and Mbaye and Bilgen [10]. An alternative fixed-grid approach is considered in this paper where the convection terms in the momentum equations are set to zero when the temperature of the phase change material (PCM) falls below the freezing isotherm and the phase change is simulated using variations in the specific heat capacity of the PCM, thus directly impinging upon the energy equation. This technique, outlined in the paper of Scanlon and Stickland [11], is applied to two cases which demonstrate its efficacy for the prediction of melting and freezing with coupled natural convection heat transfer. The first case concerns the freezing of water on the vertical wall of a rectangular cavity following the work of Braga and Viskantha [12]. This work has additional interest as the temperature range falls within that which the density inversion phenomenon occurs within water. This leads to some interesting buoyancy-driven flow patterns and ice structures. The second case deals with the natural convection melting of Lauric acid in a rectangular cavity following the work of Bose et al [13]. Once again, the non-linearities within this natural convection phase change problem promote unusual flow patterns in the form of Benard convection rolls. 


\begin{tabular}{|c|c|c|c|}
\hline \multicolumn{4}{|c|}{ NOMENCLATURE } \\
\hline $\mathrm{CO}$ & coefficient of linearised source term & \multicolumn{2}{|c|}{ Greek symbols } \\
\hline$c_{p}$ & specific heat capacity & $\alpha$ & thermal diffusivity \\
\hline$g$ & acceleration due to gravity & $\beta$ & coefficient of thermal expansion \\
\hline$h$ & specific enthalpy & $\Delta h$ & latent heat \\
\hline$k$ & thermal conductivity & $\Delta T$ & temperature bandwidth over which \\
\hline$L$ & characteristic length in Eq.(5) & & phase change is assumed to occur \\
\hline$p$ & pressure & $\phi$ & transported variable \\
\hline PCM & acronym for phase change material & $\mu$ & dynamic viscosity \\
\hline PCZ & acronym for phase change zone & $\rho$ & mass density \\
\hline $\operatorname{Pr}$ & Prandtl number, & & kinematic viscosity \\
\hline$q$ & constant, Eq. $(4)=1.894816$ & & \\
\hline$R$ & density distribution parameter, & Sub & ripts \\
\hline$R a$ & Rayleigh number, Eq.(5) & & \\
\hline$S$ & linearised source term & $c$ & cold \\
\hline$t$ & time & fus & fusion \\
\hline$T$ & temperature & $h$ & hot \\
\hline $\boldsymbol{u}$ & velocity vector & $i$ & initial condition \\
\hline$V A L$ & value of linearised source term & $l$ & liquid phase \\
\hline$w$ & constant, Eq. $(4)=9.2793 \times 10^{-6}$ & $m$ & maximum \\
\hline $\mathrm{X}, \mathrm{Y}$ & coordinate direction & $s$ & solid phase \\
\hline
\end{tabular}

\section{NUMERICAL METHOD}

Numerical analyses of melting and freezing have been carried out. The following equations have been solved within the framework of the commercially available finite volume CFD code Fluent [14] with additional subroutines incorporated in order to account for the phase change:

Continuity equation:

$$
\frac{\partial \rho}{\partial t}+\nabla \cdot \rho \boldsymbol{u}=0
$$

Momentum equation:

$$
\frac{\partial \rho \boldsymbol{u}}{\partial t}+\nabla \cdot(\rho \boldsymbol{u} \boldsymbol{u})=-\nabla p+\nabla \cdot(\mu \nabla \boldsymbol{u})+\rho \boldsymbol{g}
$$

Temperature energy equation:

$$
\frac{\partial \rho c_{p} T}{\partial t}+\nabla \cdot\left(\rho \boldsymbol{u} c_{p} T\right)=\nabla \cdot(k \nabla T)
$$

Equations (2) and (3) have been modified in order to account for the following features of the flow:

\section{FREEZING CASE}

1) The density inversion within water between $0.01{ }^{\circ} \mathrm{C}$ to $10.2{ }^{\circ} \mathrm{C}$ within which the density follows a non-linear path, attaining its maximum value at approximately $4{ }^{\circ} \mathrm{C}$. This density-temperature relationshin has been formulated bv Gebhart and 
where $\rho_{m}$ is the maximum density $\left(999.972 \mathrm{~kg} / \mathrm{m}^{3}\right.$ ) and $w=9.2793 \times 10^{-6}\left({ }^{\circ} \mathrm{C}\right)^{-\mathrm{q}}, T_{m}=4.0293{ }^{\circ} \mathrm{C}$ and $\mathrm{q}=$ 1.894816 are constant values proposed by Gebhart and Mollendorf. A non-Boussinesq approach is applied and the density varies in all terms of the transport equations.

The value of the thermal expansion coefficient

2) Other property-temperature $(\mathrm{K})$ relationships for water were as follows:

Table 1 Thermonhvsical nronerties of water

\begin{tabular}{|c|c|c|}
\hline \multirow{2}{*}{$\begin{array}{c}\text { Property } \\
\text { and units }\end{array}$} & Phase & Value of the property \\
\hline$\left.\rho \mathrm{kg} / \mathrm{m}^{3}\right]$ & Solid & 917 \\
\cline { 2 - 3 }$C p$ & Siquid & Equation (4) \\
\hline \multirow{2}{*}[\mathrm{J}/\mathrm{kgK}]{} & Liquid & 2217 \\
\hline \multirow{2}{*}{$k$} & Solid & 4180 \\
\cline { 2 - 3 }$[\mathrm{W} / \mathrm{mK}]$ & Liquid & 1.918 \\
\hline$\mu$ & Liquid & $\begin{array}{r}0.578 \\
1.91 \mathrm{e}-5 \mathrm{~T}^{2}- \\
2.141 \mathrm{e}-8 \mathrm{~T}^{3}\end{array}$ \\
\hline $\mathrm{kg} / \mathrm{ms}]$ & & $5 \mathrm{~T}+$ \\
\hline
\end{tabular}

3) The energy and momentum equations are solved in such a manner that if the temperature falls below $0.01{ }^{\circ} \mathrm{C}$ within any iteration within any numerical time step the convection terms within these equations are effectively disengaged by providing a large zero source term into the momentum equations. This will allow only transient, diffusion and source terms to influence this 'psuedosolidified' region.

4) A 'phase change zone' (PCZ) is identified and this region is confined to lie within a particular temperature bandwidth $\Delta T$, which typically has a range $-0.5{ }^{\circ} \mathrm{C}<\Delta T<0.01{ }^{\circ} \mathrm{C}$. It is within this bandwidth that phase change is assumed to occur and thus the variation in $c_{p(m u s h)}$ contained within the transient term of the energy equation may be written as $c_{p(P C Z)}=\Delta h_{\text {fus }} / \Delta T$ where $\Delta h_{\text {fus }}$ is the latent heat of fucion (ise to wrater) ac detailed in Fioure 1

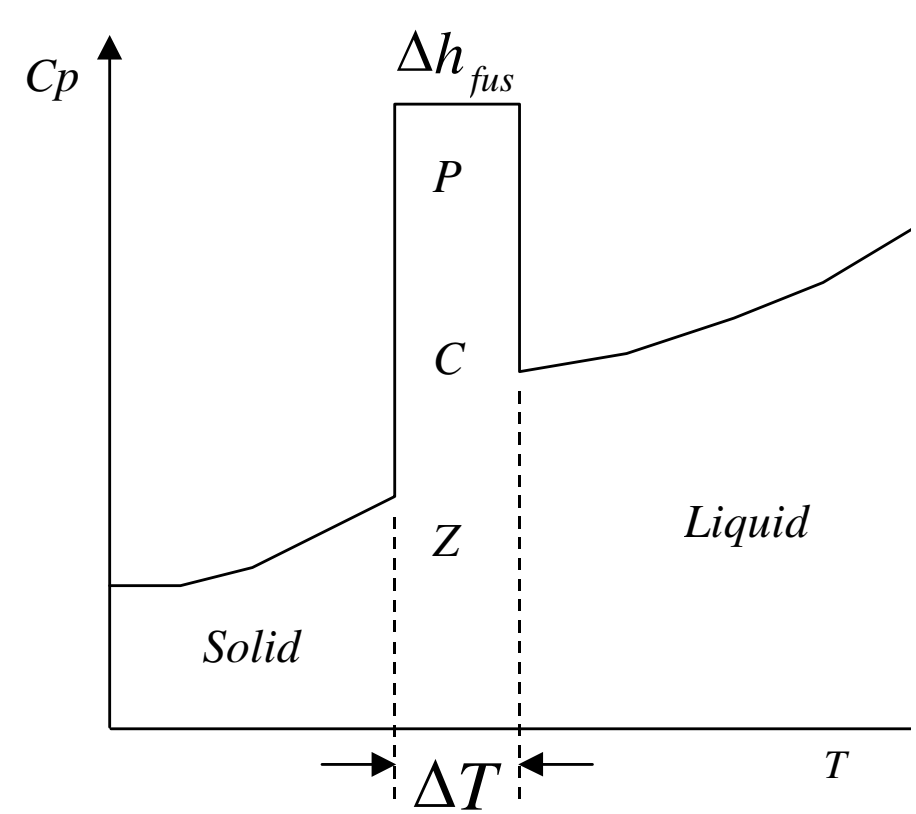

FIG. 1. Variation in specific heat capacity $c_{p}$ against temperature

For water $\Delta h_{\text {fus }}$ is taken to be $333 \mathrm{~kJ} / \mathrm{kg}$ and $\Delta T$ was set to be $0.5{ }^{\circ} \mathrm{C}$. This leads to a value for $c_{p}$ in the $\mathrm{PCZ}$ of $666 \mathrm{~kJ} / \mathrm{kg}$.

5) The experimental criteria to be modelled are outlined in Table 2 below:

Table 2. Experimental conditions for water freezing

\begin{tabular}{|c|c|c|c|c|}
\hline $\begin{array}{c}T_{h} \\
\left({ }^{\circ} \mathrm{C}\right)\end{array}$ & $\begin{array}{c}T_{c} \\
\left({ }^{\circ} \mathrm{C}\right)\end{array}$ & $\begin{array}{c}R a \\
\left(\times 10^{-8}\right)\end{array}$ & $R$ & $\operatorname{Pr}$ \\
\hline 10.2 & -10 & 1.07 & 0.39 & 11.4 \\
\hline
\end{tabular}

The above variables are based on initial temperature and length values such that Rayleigh number is defined as

$$
R a=\frac{g \beta\left(T_{i}-T_{\text {fus }}\right) L^{3}}{v \alpha}
$$

where $T_{f u s}$ is the fusion temperature $\left(0.01^{\circ} \mathrm{C}\right)$ and $L$ is the side wall height. The density distribution parameter as defined by Braga and Viskantha [12] is given as $R=\left(T_{m}-T_{\text {fus }}\right) /\left(T_{\text {wat }}-T_{\text {fus }}\right)$.

6) For the numerical solution the pressure-velocity coupling is accounted for using the SIMPLE [16] algorithm. Convective discretisation employed the QUICK [17] scheme for all transported variables. 
Temporal discretisation is first order, fully implicit. Grid sensitivity trials resulted in a final grid of 60,000 rectangular orthogonal cells while time step sensitivity analyses resulted in an optimum time step size of 4 seconds. This led to calculation times typically of 40 hours on a Pentium IV PC and the solution was declared converged within each time step when the global sum of the mass, momentum and thermal residuals were 0.001 times their initial values.

\section{MELTING CASE}

1) For the case of the melting of Lauric acid following the work of Bose et al [13] the following table describes the thermophysical properties of the PCM.

Table 3. Thermophysical properties of Lauric acid

\begin{tabular}{|c|c|c|}
\hline $\begin{array}{c}\text { Property } \\
\text { and units }\end{array}$ & Phase & Value of the property \\
\hline$\rho$ & Solid & 1005.5 \\
\cline { 2 - 3 }$\left[\mathrm{kg} / \mathrm{m}^{3}\right]$ & Liquid & $1114.8-0.76 \mathrm{~T}$ \\
\hline$C p$ & Solid & 2155 \\
\cline { 2 - 3 }$[\mathrm{J} / \mathrm{kgK}]$ & Liquid & 2394 \\
\hline$k$ & Solid & $0.661-0.0016 \mathrm{~T}$ \\
\cline { 2 - 3 }$[\mathrm{W} / \mathrm{mK}]$ & Liquid & \begin{tabular}{c}
$0.661-0.0016 \mathrm{~T}$ \\
\hline$\mu$
\end{tabular} \\
\hline $\mathrm{kg} / \mathrm{ms}]$ & Liquid & $\begin{array}{r}0.2503-0.0013 \mathrm{~T}+ \\
2 . \mathrm{e}-6 \mathrm{~T}^{2}\end{array}$ \\
\hline
\end{tabular}

Note that the above values of $\mathrm{T}$ are in $\mathrm{K}$ and no information was available for $k$ for the solid phase.

2) The melting temperature for Lauric acid was taken as $43.5^{\circ} \mathrm{C}$ and the PCZ was set to be in the range $43{ }^{\circ} \mathrm{C}<\Delta T<43.5{ }^{\circ} \mathrm{C}$. For the PCM $\Delta h_{\text {fus }}$ is taken to be $183 \mathrm{~kJ} / \mathrm{kg}$ and $\Delta T$ was set to be $0.5{ }^{\circ} \mathrm{C}$. This leads to a value for $c_{p}$ in the PCZ of $366 \mathrm{~kJ} / \mathrm{kg}$.

3) The experimental criteria to be modelled are outlined in Table 4:
Table 4. Experimental conditions for Lauric acid melting

\begin{tabular}{|c|c|c|c|}
\hline $\begin{array}{c}T_{h} \\
\left({ }^{\circ} \mathrm{C}\right)\end{array}$ & $\begin{array}{c}T_{c} \\
\left({ }^{\circ} \mathrm{C}\right)\end{array}$ & $\begin{array}{c}R a \\
\left(\times 10^{-6}\right)\end{array}$ & $\operatorname{Pr}$ \\
\hline 65 & 42 & 5.45 & 119 \\
\hline
\end{tabular}

The above variables are based on initial temperature and length values such that Rayleigh number is defined as

$$
R a=\frac{g \beta\left(T_{h}-T_{c}\right) L^{3}}{v \alpha}
$$

where $L$ is the vertical side wall heater height $(2.54$ $\mathrm{cm})$.

4) As with the freezing study a non-Boussinesq approach is applied and the density varies in all terms of the transport equations according to the relationship outlined in table 3 .

5) For the numerical solution the pressure-velocity coupling is accounted for using the SIMPLE [15] algorithm. Convective discretisation employed the QUICK [16] scheme for all transported variables. Temporal discretisation is first order, fully implicit. Grid sensitivity trials resulted in a final grid of 43,000 rectangular orthogonal cells while time step sensitivity analyses resulted in an optimum time step size of 4 seconds. This led to calculation times typically of 30 hours on a Pentium IV PC and the solution was declared converged within each time step when the global sum of the mass, momentum and thermal residuals were 0.001 times their initial values.

6) Due to thermal inertia of the heater mechanism used by Bose et al [13] the outer surface temperature took a finite amount of time to reach its set value $\left(65^{\circ} \mathrm{C}\right)$. This time period was estimated to be 5 minutes and a linear approximation for this boundary condition was applied as follows:

$$
T_{h}=315.15+0.0767 t
$$

\section{EXPERIMENTAL DETAILS}

\section{FREEZING CASE}

The water freezing experiment is that of Braga and Viskantha [12]. Details of the freezing experiment are shown in figure 2 : 


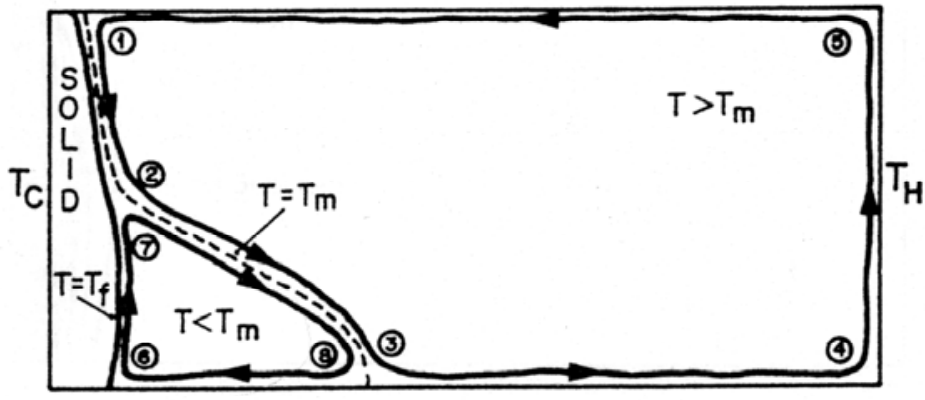

Figure 2 Water freezing experiment of Braga and Viskantha [12]

The experiments were conducted using a rectangular water-filled cavity having inside dimensions of $150 \mathrm{~mm}$ in height, $300 \mathrm{~mm}$ in width and $75 \mathrm{~mm}$ in depth. Figure 2 is a schematic diagram of the experimental rig and shows a left hand vertical cold wall and a right hand vertical hot wall. The top and bottom walls are adiabatic. The initial temperature of the water in the cavity is $T_{h}$ and the transient freezing experiment is commenced when the cold wall temperature is initiated. The values selected for $T_{h}$ and $T_{c}$ are provided in Table 2 . Temperature variations across the depth of the cavity confirmed the resulting flow patterns as two dimensional in nature.

Due to the non-linear density-temperature relationship for water over this temperature range we find some interesting flow patterns occurring. After a time period of 1 hour has elapsed we discover a natural convection flow field consisting of two counter rotating circulations. The smaller eddy, located in the lower left hand corner, is clockwise in nature and is encapsulated within a temperature field where the temperature $T$ is always less than $T_{m}$, the temperature corresponding to the maximum density. Beyond this temperature range a larger counter clockwise circulation is evident where the temperature $T$ is always greater than $T_{m}$. The ice crystal growth on the cold wall is observed to be non-linear and possesses a thicker base in the region adjacent to the colder, smaller clockwise eddy.

Thermocouples were placed at various locations within the flow field and two of these were selected for a comparison of the temperature-time evolutions between the experiment and the numerical simulation. The locations of these two thermocouples are shown in table 5 and describe the $x, y$ position from the lower, left hand internal corner of the cavity.
Table 5 Thermocouple locations for comparison with CFD

\begin{tabular}{|c|c|c|}
\hline \multirow{2}{*}{$\begin{array}{c}\text { Thermocouple } \\
\text { name }\end{array}$} & \multicolumn{2}{|c|}{ Iocation } \\
\cline { 2 - 3 } & $\begin{array}{c}x \\
(\mathrm{~mm})\end{array}$ & $\begin{array}{c}y \\
(\mathrm{~mm})\end{array}$ \\
\hline$T C 1$ & 50 & 20 \\
\hline$T C 2$ & 150 & 75 \\
\hline
\end{tabular}

\section{MELTING CASE}

The melting experiment is that of Bose et al [13] and considers the melting of $95 \%$ pure Lauric acid. An outline sketch of the experiment is shown in figure 3, with the dimensions in inches.

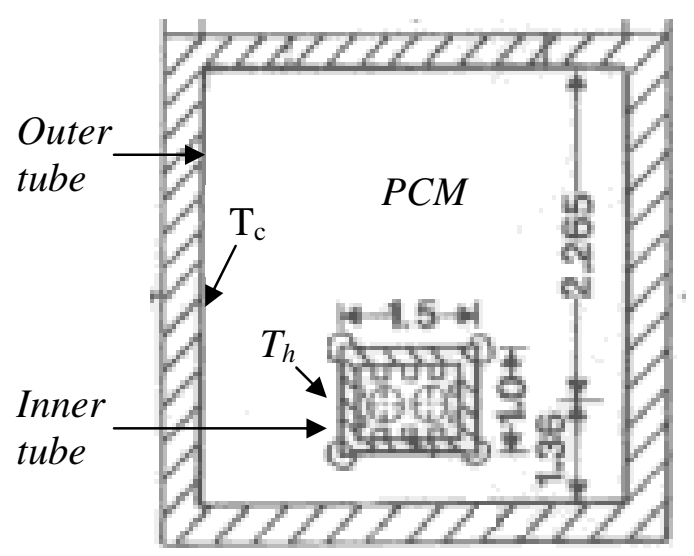

Figure 3 Lauric acid melting experiment of Bose et al [13]

The rig itself consists of a long outer tube of square cross-section with an equally long inner tube of rectangular cross-section located inside it, as shown in figure 3. The void between these two tubes was filled with $95 \%$ pure Lauric acid, which served as the phase change material (PCM). In the experiment considered, the entire test cell and the PCM were heated initially to a uniform temperature, $T_{c}$, just below the melting temperature, $T_{f u s}$. Then, the outer tube temperature was maintained at $T_{c}$ throughout the duration of the experiment. At the start of the experimental run the inner tube temperature was raised to $T_{h}$ and then maintained constant throughout the run. Consequently, the PCM melted and resulted in some interesting flow and PCM patterns. 


\section{RESULTS AND DISCUSSION}

\section{FREEZING CASE}

In the work of Braga and Viskantha [12] qualitative results showing the ice growth and resulting flow patterns were captured using time-lapse still photography. The water itself had been seeded with a small amount of neutrally buoyant particles and illumination was provided using a sheet of laser light.

The results shown in figure 4 show the comparison between experimental and numerical trials for the thermocouple positions outlined in table 5:

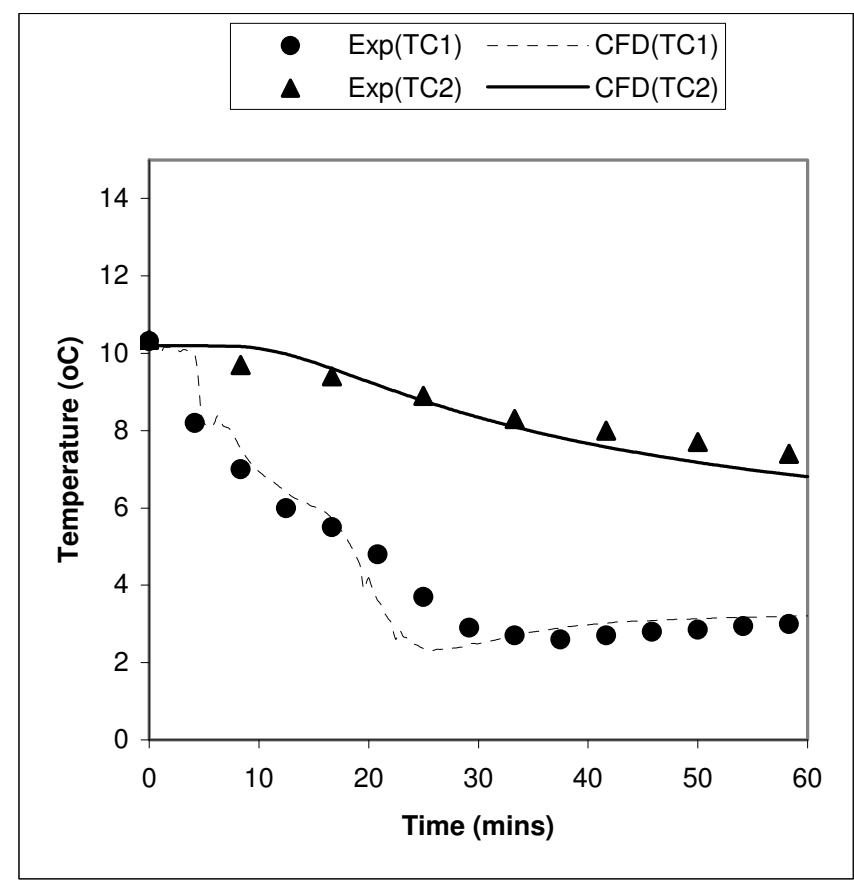

Figure 4 Experimental and numerical temporal evolution of temperature at thermocouples TC1 and TC2.

These results show a reasonable quantitative concurrence of the CFD prediction compared with that obtained experimentally. The temperature profile for thermocouple TC1 is seen to decay rather sharply over the first 20 minutes of the transient and is captured reasonably well by the numerical approach. After 20 minutes the CFD solution tends to under predict the temperature, perhaps as a consequence of not capturing the ice crystal growth to its full extent. The general trends, however, appear to be correct for both thermocouple positions TC1 and TC2, in particular TC2 is well captured.
Qualitative images of the numerical and experimental flow patterns and ice accretion are shown in figures 5 to 10 .

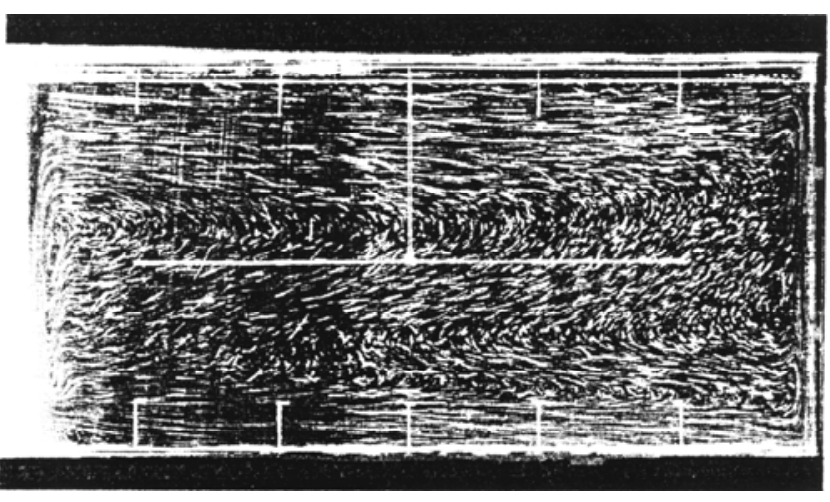

Figure 5 Photograph of flow patterns and ice accretion, $t=15$ mins, Braga and Viskantha [12]

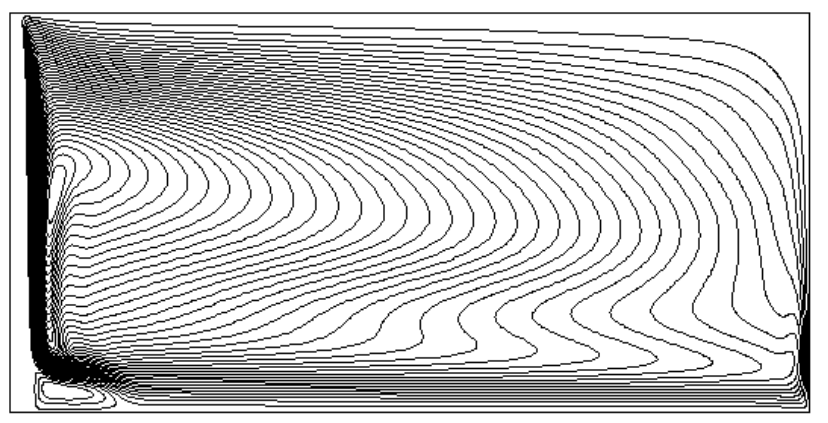

Figure 6 Numerical prediction of flow patterns (streamlines) and ice accretion, $t=15 \mathrm{mins}$

Figures 5 and 6 demonstrate a reasonable qualitative correlation between the numerical and experimental trials after a 15 minute time interval. The flow patterns shows a general anticlockwise larger circulation with a smaller clockwise eddy appearing in the lower left hand corner due to the effects of density inversion. The general anticlockwise flow is seen to change direction in an s-type pattern around the horizontal mid-plane of the cavity before being entrained into the colder flowing water near the base of the cavity. The colder down flow on the ice surface is also seen to separate towards the base and reattaches on the base wall.

The ice accretion on the left hand vertical cold wall is seen to be thicker towards its base. This will be as a consequence of the smaller circulation maintaining a colder temperature below $T_{m}$. 
Figures 7 and 8 show the flow patters and ice growth after a time interval of 1 hour.

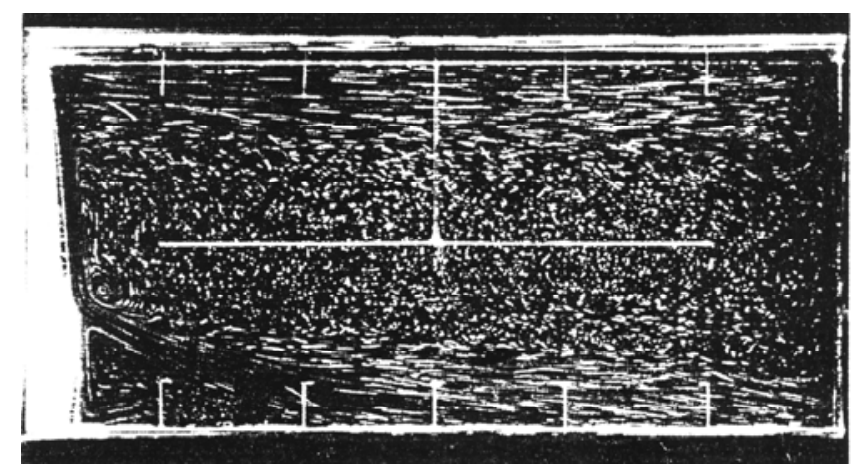

Figure 7 Photograph of flow patterns and ice accretion, $t=60$ mins, Braga and Viskantha [12]

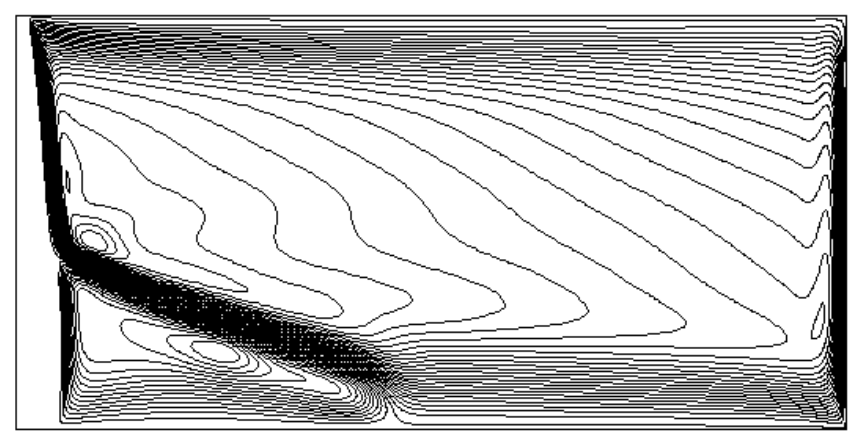

Figure 8 Numerical prediction of flow patterns (streamlines) and ice accretion, $t=60 \mathrm{mins}$

The above figures detail a larger anticlockwise natural convection circulation where warmer fluid rises on the heated vertical right hand wall and flows along the upper ceiling of the cavity. As this flow encounters the ice crystal it descends until its temperature reaches $T_{m}$, the temperature corresponding to the maximum density. At this point the boundary layer flow separates from the ice and continues in a shallow downward diagonal path to reattach itself on the base floor of the cavity near to the vertical centerline. The smaller clockwise circulation, within which $T<T_{m}$, is seen to have grown in comparison with $t=15$ minutes. The numerical and experimental trials appear to be in reasonable agreement for the general flow patterns encountered.

The ice growth is observed to be non-uniform in nature with a distinct kink in the ice pattern at the separation point. The ice base is thicker due to the smaller eddy containing colder fluid thus reducing the convective heat loss from the ice to the water. The numerical prediction appears to have captured the gross features of the ice growth, namely ice thickness, vertical profile and kink location. The kink location does appear to be, however, slightly higher up on the ice crystal in comparison with experiment. Figures 9 and 10 show this region in closer detail.

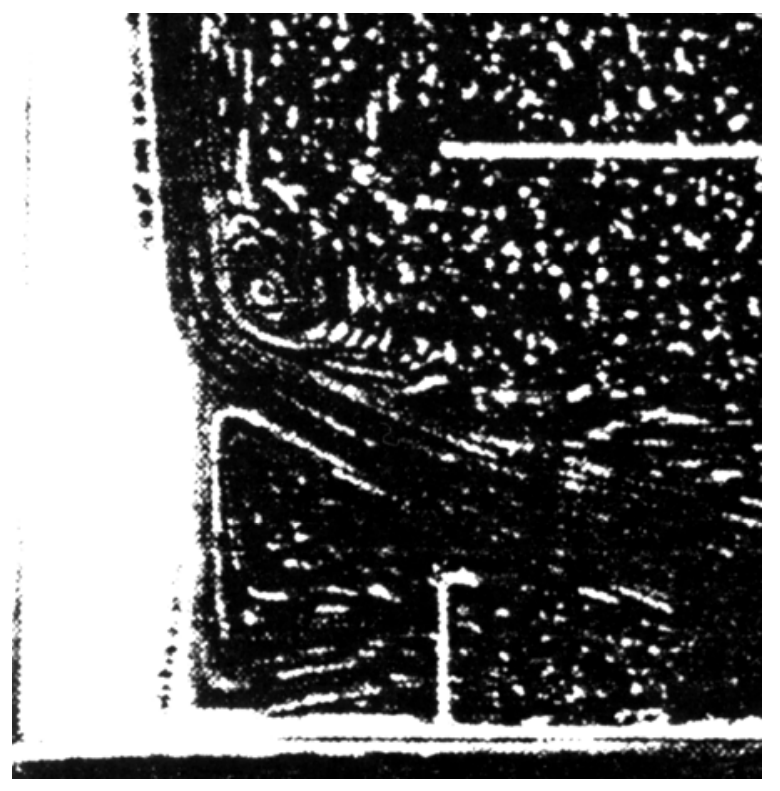

Figure 9 Close up photograph of flow separation region, $t=60$ mins, Braga and Viskantha [12]

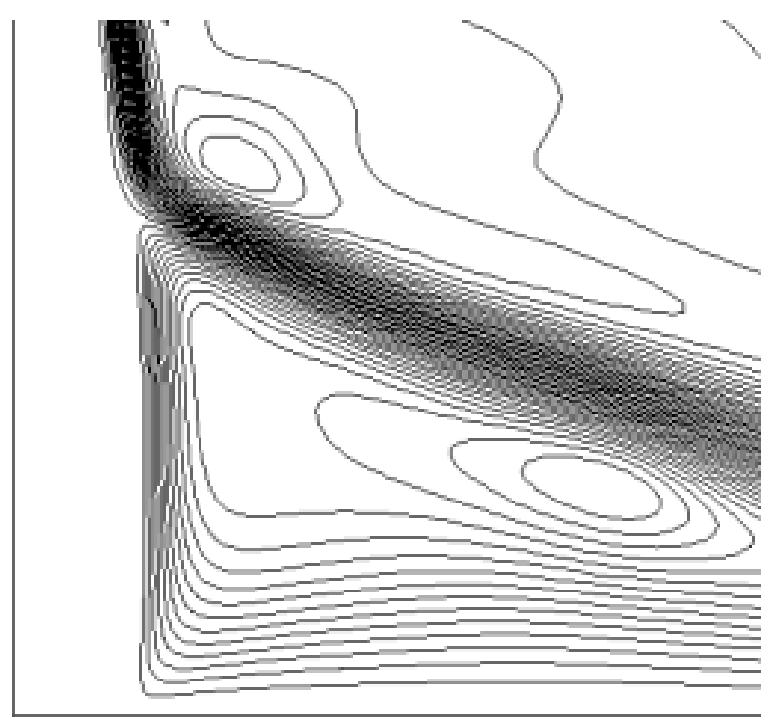

Figure 10 Close up numerical prediction (streamlines) of flow separation region, $t=60 \mathrm{mins}$ 


\section{MELTING CASE}

The following results highlight the qualitative comparisons between the experimental melting of 95\% pure Lauric acid after Bose et al [13] and the numerical approach outlined in this paper.

Figures 11 and 12 show the temporal evolution of the melt interface.

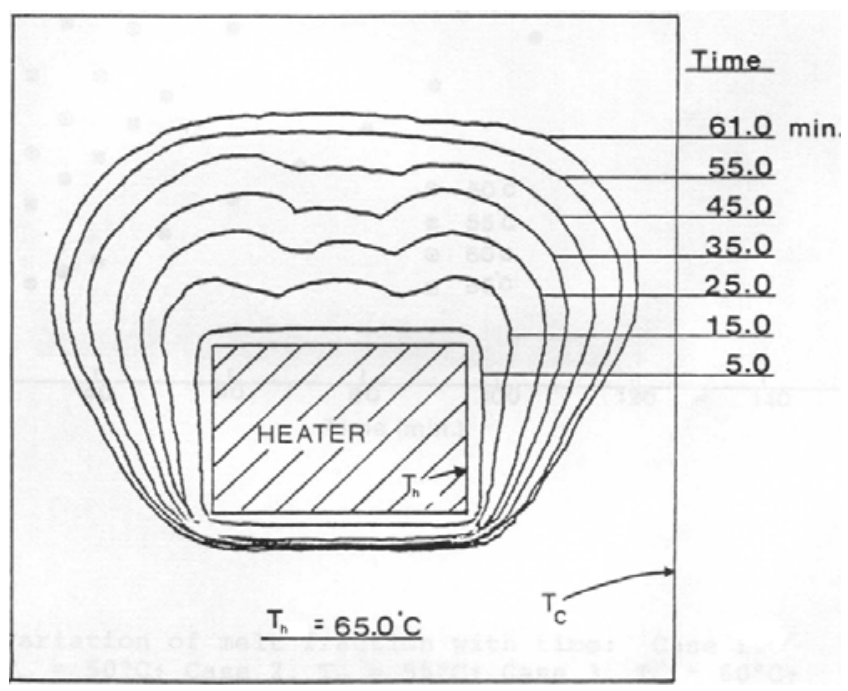

Figure 11 Experimental transient interface profiles, Bose et al [13]

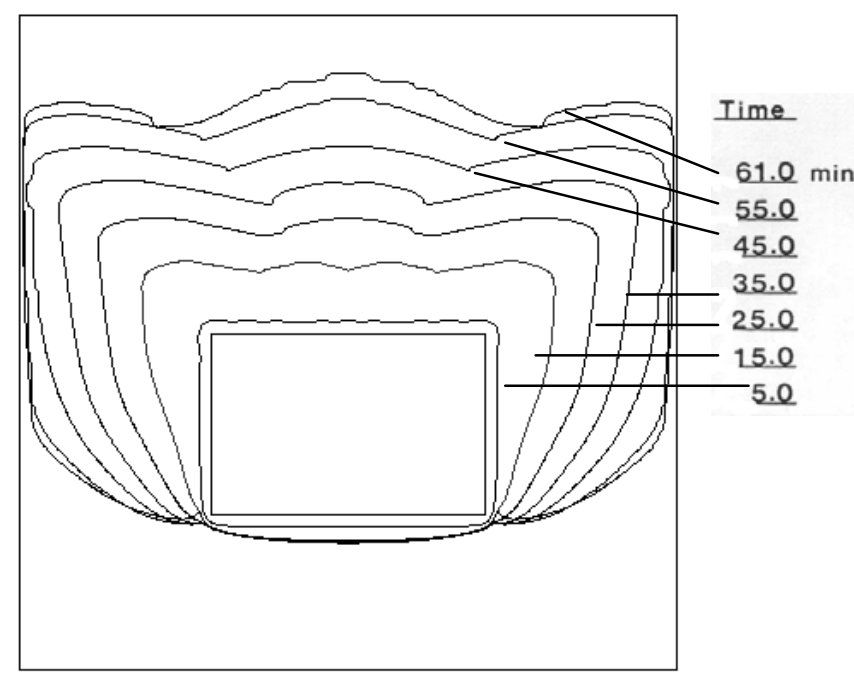

Figure 12 Numerical transient interface profiles

Figures 11 and 12 highlight a general accord between the flow patterns and interface characteristics for the experimental and numerical results. The experimental results show a high degree of symmetry and thus the numerical solution solution was considered as a symmetric half. Although there is general agreement, it is observed that the numerical results do appear to predict a much faster melting rate. This manifests itself in figure 12 which shows the influence of this enhanced melting rate via the predicted interface position with time. The numerical results also appear to be flatter in the upper part of the convection melt and, although the predicted vertical penetration seems reasonable, the horizontal penetration is observed to be greater than that found experimentally using a digital planimeter.

The results show a melting profile where the upper part of the melt is controlled by natural convection processes while the lower half appears to be diffusion dominated. Bose et al [13] have postulated that the highly non-linear solid-liquid interface profiles are a result of Bénard type convection rolls. Figure 13 highlights such flows during the numerical solution

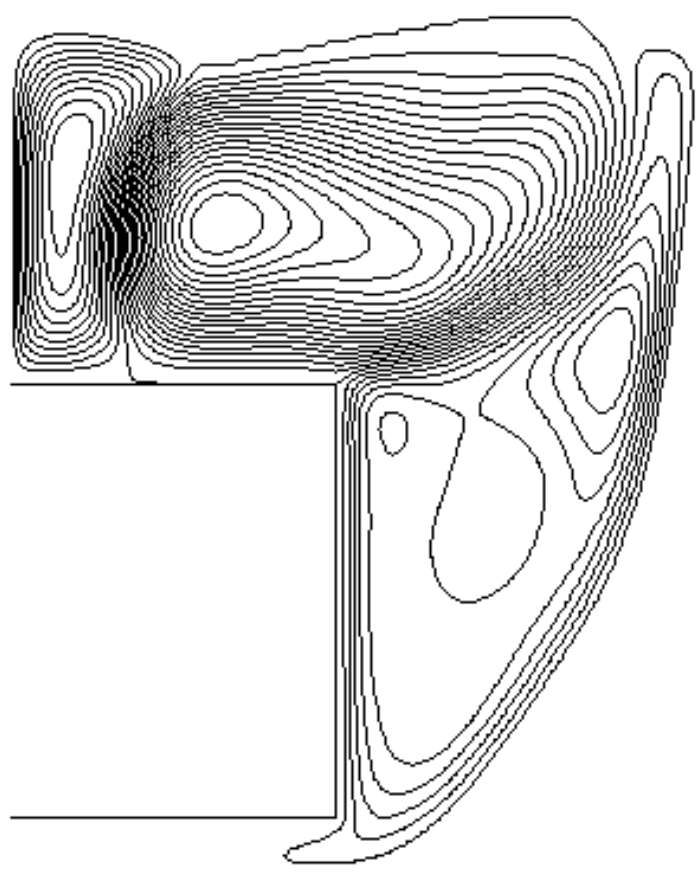

Figure 13 Numerical prediction (symmetrical half) of streamlines showing Bénard convection cells, $t=$ 35 mins

Figure 13 highlights the significance of the multicellular flow patterns on the formation shape of the melt interface for Lauric acid. Such multi-cellular flow activity is observed to effectively 'bite' into the solid PCM and results in the wave patterns 


\section{CONCLUSIONS}

A numerical investigation of buoyancy-driven melting and freezing has been carried out. The results show that such complex transient phenomena can be adequately captured using a relatively straightforward numerical technique. The gross features of the natural convection freezing of water and the melting of $95 \%$ pure Lauric acid, including for such effects as density inversion and multi-cellular flow patterns, appear to have been captured.

\section{REFERENCES}

[1] Goldstein, R. J. and Ramsey, J. W. Heat transfer to a melting solid with application to thermal energy storage systems, in Studies in Heat Transfer, A Festschrift for E.R.G. Eckert, J.P. Hartnet et al., Eds.,pp. 199-208, McGraw-Hill, Washington D.C., 1979.

[2] Ostrach, S., Fluid mechanics in crystal growth, ASME J. Fluids Engineering, Vol. 105, pp. 5-20, 1983.

[3] Feldman, D., Shapiro, M.M., Banu, D. and Fuks, C.J., Fatty acids and their mixtures as phase-change material for thermal energy storage, Solar Energy Materials, Vol. 18, pp. 201-216, 1989.

[4] Viskanta, R., Natural convection in melting and solidification, in Natural Convection: Fundamentals and Applications, S. Kakac et al, Eds., Hemisphere, Washington D.C., pp. 845-877, 1985.

[5] Yao, L.S. and Prusa, J., Melting and freezing, in Advances in Heat Transfer, Academic Press, Vol. 19, pp. 1-95, 1989.

[6] Prescott, P.J. and Incropera, F.P., Convection heat and mass transfer in alloy solidification, in Advances in Heat Transfer, Academic Press, Vol. 28, pp. 231-338, 1996.

[7] Usmani, A.S., Lewis, R.W. and Seetharamu, K.N. Finite element modeling of naturalconvection-controlled change of phase, Int. J. for Num. Meth. Fluids, Vol. 14, pp. 10191036, 1992.

[8] Oosthuizen, P.H., A numerical study of the steady state freezing of water in a rectangular enclosure, in Numerical Methods in Thermal Problems, R.W. Lewis Ed., Pineridge Press, Vol. VIII, Part I, pp. 92-103, 1993.
[9] Swaminathan, C.R. and Voller, V.R., Towards a general numerical method for analysis of solidification systems, Int. J. Heat Mass Trans., Vol. 40, 2859-2868., 1997.

[10] Mbaye, M. and Bilgen, E., Phase change process by natural convection-diffusion in rectangular enclosures, Heat and Mass Transfer, Vol. 37, pp. 35-42, 2001.

[11] Scanlon, T.J. and Stickland, M.T., An experimental and numerical investigation of natural convection melting, Int. Comm. Heat Mass Trans., Vol. 28, pp. 181-190, 2001.

[12] Braga, S.L. and Viskanta, R. Effect of density extremum on the solidification of water on a vertical wall of a rectangular cavity, Experimental Thermal and Fluid Science, Vol. 5, pp. 703-713, 1992.

[13] Bose, A., Scott, D.A. and Baliga, B.R., An experimental investigation of melting in the presence of natural convection, Proceedings of the First International Conference on HeatTransfer, Fluid Mechanics and Thermodynamics, (Editor: Meyer JP), Vol. 1, Part 2, pp. 678-683, Kruger National Park, Skukuza, South Africa, 8-10 April, 2002.

[14] www.fluent.com

[15] Gebhart, B. and Mollendorf, J.C. A New Density Relation for Pure and Saline Water, Deep Sea Res., Vol. 24, pp. 831-848, 1977.

[16] Patankar, S.V., Numerical Heat Transfer and Fluid Flow, Hemisphere, New York, 1980.

[17] Leonard, B.P., A stable and accurate convective modelling procedure based on quadratic upstream interpolation, Comp. Meth. in Appl. Mech. and Eng., Vol. 19, pp. 59-98, 1979. 